\title{
INTERACTION OF BURIED PIPELINE WITH SOIL UNDER DIFFERENT LOADING CASES
}

Martin MAGURA ${ }^{1 *}$

\section{Abstract}

Gas pipelines pass through different topographies. Their stress level is influenced not only by gas pressure, but also by the adjacent soil, the thickness of any covering layers, and soil movements (sinking, landslides). The stress level may be unevenly spread over a pipe due to these causes. When evaluating experimental measurements, errors may occur. The value of the resistance reserve of steel can be adjusted by a detailed analysis of any loading. This reserve can be used in the assessment of a pipeline's actual state or in reconstructions. A detailed analysis of such loading and its comparison with the simple theory of elasticity is shown in this article.

\section{Address}

1 Department of Steel and Timber Structures, Faculty of Civil Engineering, Slovak University of Technology in Bratislava, e-mail: martin.magura@stuba.sk

* Corresponding author: martin.magura@stuba.sk

\section{Key words}

- Pipeline

- Adjacent soil,

- FEM analysis,

- Landslide.

\section{CALCULATING THE STRESS LEVEL FOR A PIPELINE WITH A SIMPLE THEORY OF ELASTICITY}

In the 1970's, gas pipelines were designed according to the simple theory of elasticity.

The internal gas pressure $\mathrm{p}$, axial force $\mathrm{N}$, bending moment $\mathrm{M}$, torque moment $\mathrm{Mo}$, and shear force $\mathrm{V}$ act on a straight pipe section (a thin-walled cylindrical shell) (Fig. 1).

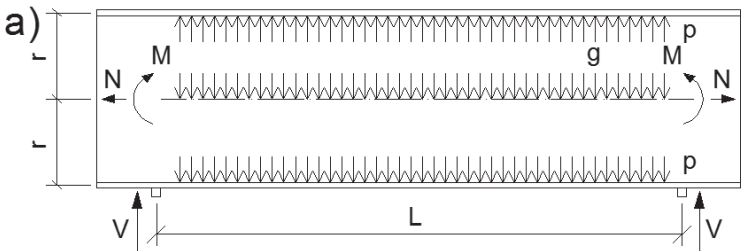

b)

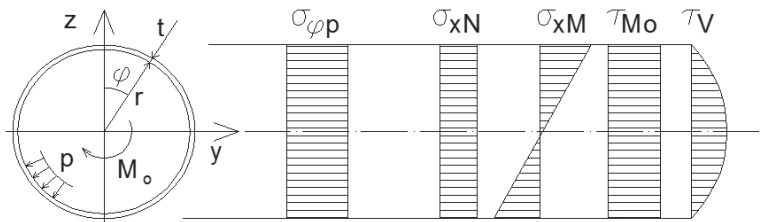

Fig. 1 Loading of a pipeline, and the stress distribution at its crosssection
Stresses induced by internal pressure $\mathrm{p}$ :

$$
\sigma_{\varphi_{p}}=\frac{p . r}{t}
$$

The general criterion for the reliability of a cross-section stressed by an axial force, bending, and shear is:

$$
\sigma_{r e d}=\sqrt{\sigma_{x}^{2}-\sigma_{x} \cdot \sigma_{\varphi_{p}}+\sigma_{\varphi_{p}}^{2}+3 \tau^{2}} \leq \frac{f_{y}}{\gamma_{M}}
$$

where $f_{y}$ yield strength, and $\gamma_{M}$ material safety factor

The results of the calculations are summarized in Table 1, where the stress levels at different values of the internal pressure of gas are presented. The reserves of material for reaching the yield strength (steel X60) are in the last column.

\section{CALCULATING THE STRESS ON A PIPE USING THE FINITE ELEMENT METHOD WHEN CONSIDERING THE EFFECT OF THE ADJACENT SOIL}

A segment of pipe with a length of $1 \mathrm{~m}$ in a soil block was modeled using Ansys 8.1 software (Fig. 2). The dimensions of the soil block were $7.2 \times 3.5 \mathrm{~m}$, with a thickness of $1 \mathrm{~m}$. The contact was mod- 
Tab. 1 Reserve of material strength at pipe X60 ø 1220/15.9

\begin{tabular}{|c|c|c|c|c|c|}
\hline $\begin{array}{c}\text { Gas pressure } \mathrm{p} \\
{[\mathrm{MPa}]}\end{array}$ & $\begin{array}{c}\text { Wall thickness } \mathrm{t}_{\mathrm{i}} \\
{[\mathrm{mm}]}\end{array}$ & $\begin{array}{c}\text { Radius } \mathrm{r}_{\mathrm{i}} \\
{[\mathrm{mm}]}\end{array}$ & $\begin{array}{c}\mathrm{s}_{\mathrm{Fp}}=\left(\mathrm{p} . \mathrm{r}_{\mathrm{i}} / \mathrm{t}_{\mathrm{i}}\right) \\
{[\mathrm{MPa}]}\end{array}$ & $\begin{array}{c}\text { fy/ } \gamma_{\mathrm{M}} \\
{[\mathrm{Mpa}]}\end{array}$ & $\begin{array}{c}\text { Reserve of stress } \Delta \mathrm{s} \\
{[\mathrm{MPa}]}\end{array}$ \\
\hline 7.00 & 15.9 & 610 & 268.55 & 296.43 & $\mathbf{2 7 . 8 8}$ \\
\hline 6.00 & 15.9 & 610 & 230.19 & 296.43 & $\mathbf{6 6 . 2 4}$ \\
\hline 5.00 & 15.9 & 610 & 191.82 & 296.43 & $\mathbf{1 0 4 . 6 0}$ \\
\hline 4.00 & 15.9 & 610 & 153.46 & 296.43 & $\mathbf{1 4 2 . 9 7}$ \\
\hline 3.00 & 15.9 & 610 & 715.09 & 296.43 & $\mathbf{1 8 1 . 3 3}$ \\
\hline 2.00 & 15.9 & 610 & 38.36 & 296.43 & $\mathbf{2 1 9 . 7 0}$ \\
\hline 1.00 & 15.9 & 610 & 0.00 & 296.43 & $\mathbf{2 5 8 . 0 6}$ \\
\hline 0.00 & 15.9 & 610 & & $\mathbf{2 9 6 . 4 3}$ \\
\hline
\end{tabular}

Tab. 2 Standardized characteristics of the soil entered into the calculations

\begin{tabular}{|c|c|c|c|c|}
\hline Soil class & $\begin{array}{c}\text { Bulk density } \\
\gamma[\mathrm{t}]\end{array}$ & $\begin{array}{c}\text { Young's Modulus } \\
\mathrm{E}_{\text {def }}[\mathrm{kPa}]\end{array}$ & $\begin{array}{c}\text { Angle of internal friction } \\
\mathrm{f}\left[{ }^{\circ}\right]\end{array}$ & $\begin{array}{c}\text { coherence } \\
\mathrm{C}[\mathrm{kPa}]\end{array}$ \\
\hline F4 - stiff consistency & 20 & 5000 & 22 & 70 \\
\hline S4 - sand & 18 & 12,000 & 30 & 0 \\
\hline G4 - gravel & 19 & 70,000 & 33 & 0 \\
\hline
\end{tabular}

eled on the gap between the pipe and soil. It allowed for the displacement of soil on the pipe's surface and only transmited compression. The coherent forces between the soil and pipe were applied with 0 values. Three types of soil were chosen for the analysis, and their characteristics are shown in Table 2. The thickness of the covering layer was $0.8 \mathrm{~m}$ (normal).

The pipe was modeled from a SOLID 186 finite element. The SOLID 45 element was used for the modeling of the adjacent soil with a Drucker-Prager non-linearity, which allows for the selection of the characteristics of the soil (e.g., the angle of internal friction or coherence).

\subsection{Pipe in the F4 class soil}

The results obtained are summarized and in the table below. It is obvious that the value of the material's resistance reserve increased in all the cases, owing to the detailed calculations.

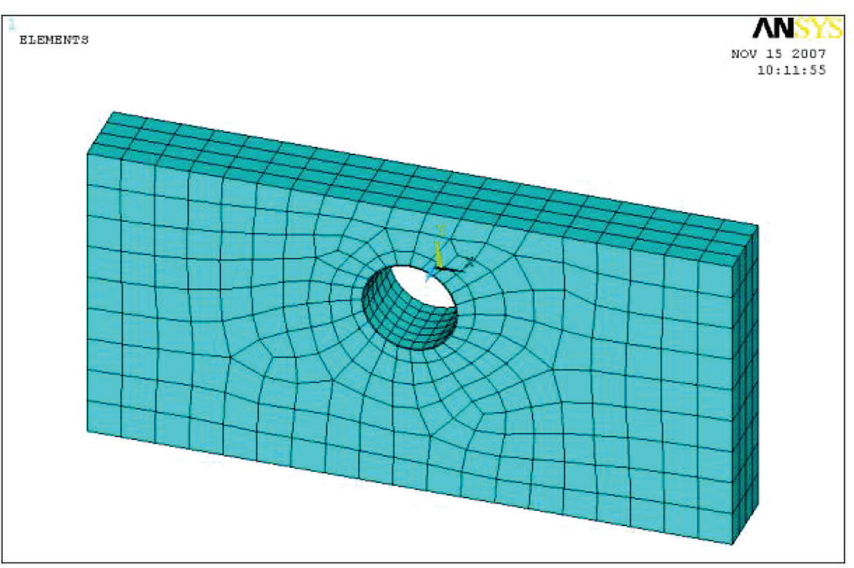

Fig. 2 Model analyzed with an embankment thickness of $0.8 \mathrm{~m}$

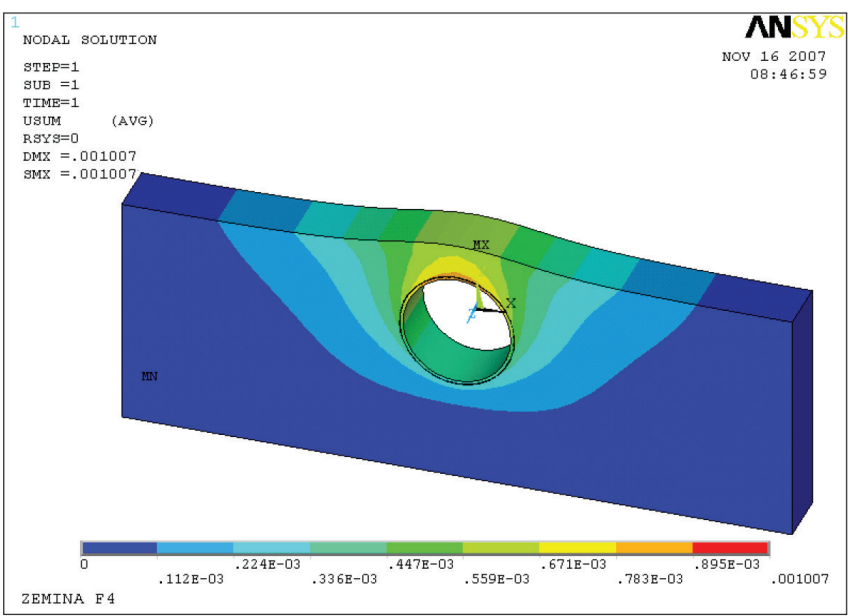

Fig. 3 Deformations from the internal pressure

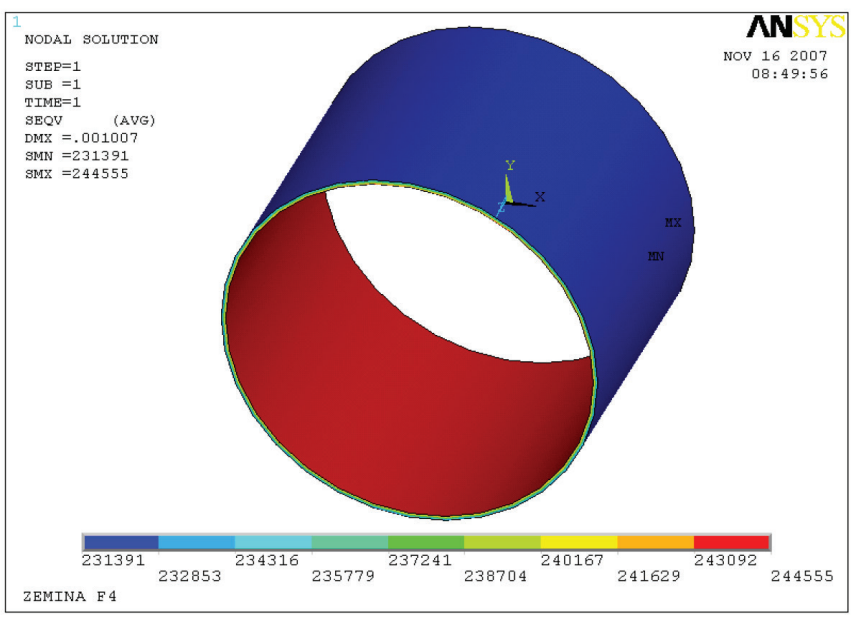

Fig. 4 Stress from internal pressure $[\mathrm{kPa}]$ 


\subsection{Pipe in S4 class soil (sand)}

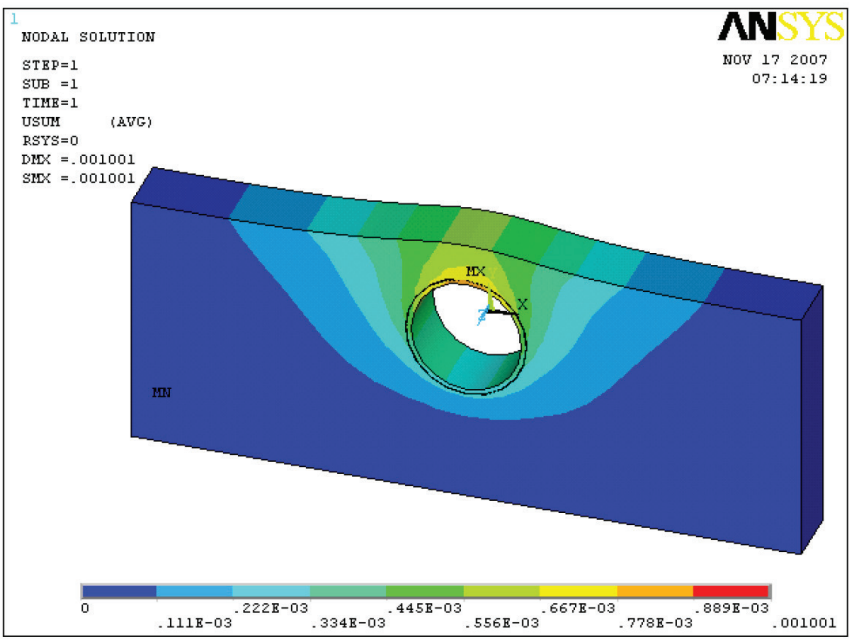

Fig. 5 Deformations from internal pressure

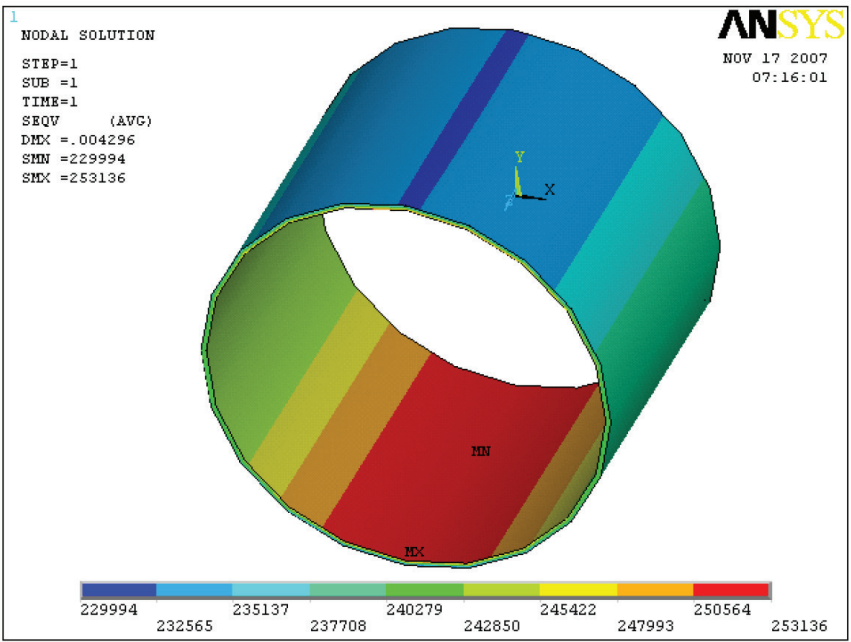

Fig. 6 Stress from internal pressure and bulk density $[\mathrm{kPa}]$

\subsection{Pipe in G4 class soil (gravel)}

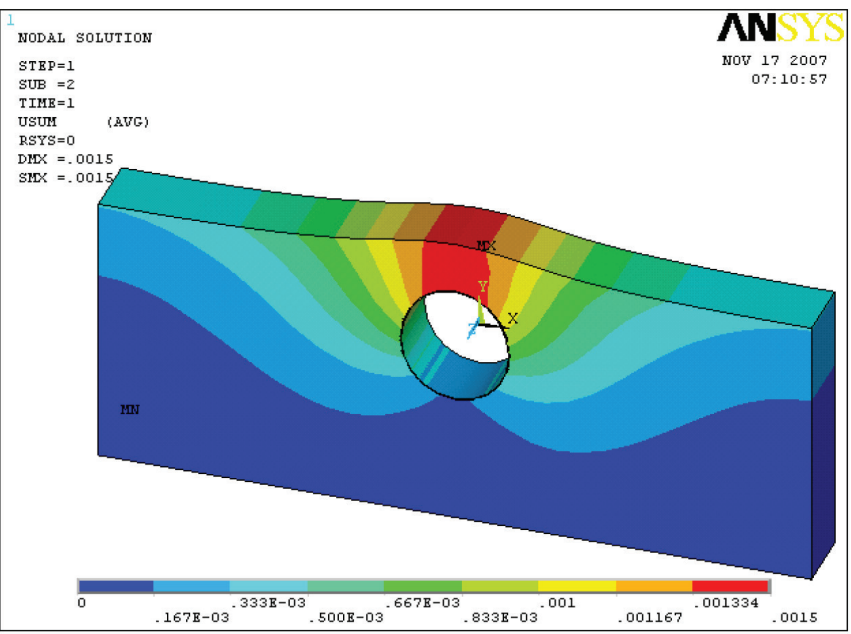

Fig. 7 Deformations from internal pressure

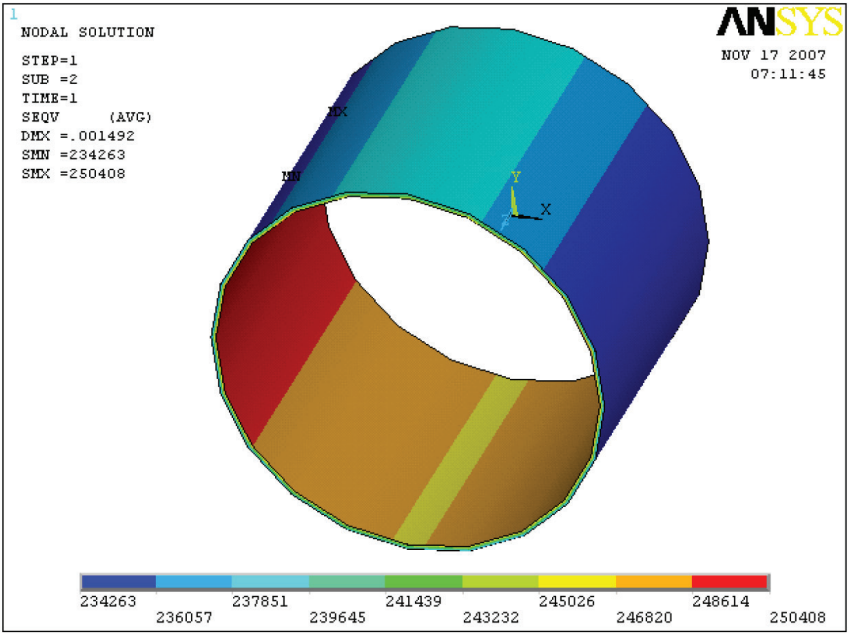

Fig. 8 Stress from internal pressure and bulk density [kPa]

Tab. 3 Comparison of stress calculated with different methods

\begin{tabular}{|c|c|c|c|c|c|c|}
\hline Class of soil & $\begin{array}{c}\text { Stress from internal } \\
\text { pressure 7 MPa (theory } \\
\text { of elasticity) [MPa] }\end{array}$ & $\begin{array}{c}\text { Stress from internal } \\
\text { pressure 7MPa(FEM) } \\
{[\mathrm{MPa}]}\end{array}$ & $\begin{array}{c}\text { Stress from bulk } \\
\text { density(FEM) } \\
{[\mathrm{MPa}]}\end{array}$ & $\begin{array}{c}\text { Stress from internal } \\
\text { pressure + bulk density } \\
\text { (FEM) [MPa] }\end{array}$ & $\begin{array}{c}\text { Difference } \\
{[\mathrm{kPa}]}\end{array}$ & $\begin{array}{c}\text { Reserve } \\
\Delta \sigma[\mathrm{MPa}]\end{array}$ \\
\hline F4 & 268.55 & 244.55 & 17.54 & 259.73 & 8.82 & 36.7 \\
\hline S4 & 268.55 & 249.06 & 4.99 & 253.14 & 15.41 & 43.29 \\
\hline G4 & 268.55 & 249.21 & 2.03 & 250.40 & 18.15 & 46.03 \\
\hline
\end{tabular}

\subsection{The effect of the thickness of the covering layer}

The layer of soil covering the pipe changes as it crosses under roads, passes through different terrain barriers, or is at the outlet of the pipe to a bridge. The piping's state of stress in a normal operating mode is also influenced by the changing of its coverage.
This effect was analyzed on two models. In the first model (Fig 9), the covering layer's thickness was increased to $1.5 \mathrm{~m}$. In the second model (Fig.10), it was reduced to $0.25 \mathrm{~m}$. The results of the analysis are summarized in Table 4, from which it is obvious that the strain under the normal operating pressure changed with a change in the covering layer to a value of $+/-9 \mathrm{MPa}$ for fine-grained soils. The change in the strain in gravels was almost negligible. 


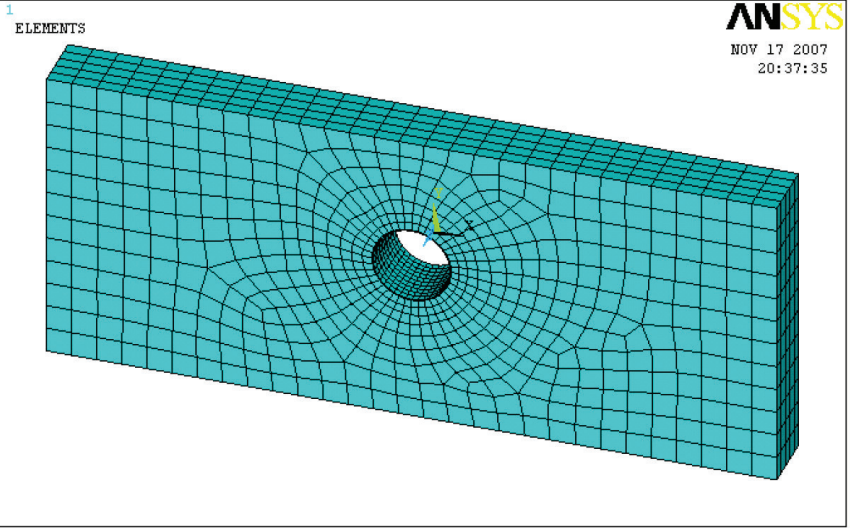

Fig. 9 Pipe with $1.5 m$ thick cover

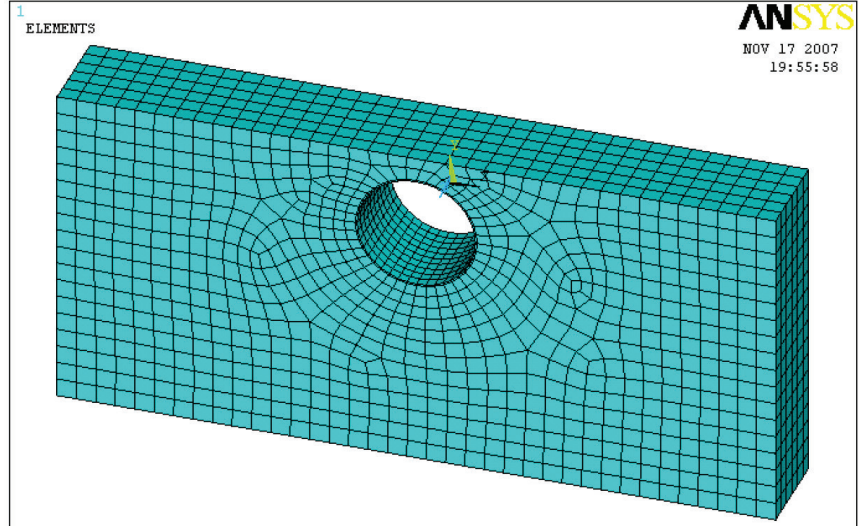

Fig. 10 Pipe with $0.25 m$ thick cover

Tab.4 Strains on the pipeline according to different thicknesses of the covering layer

\begin{tabular}{|c|c|c|c|c|}
\hline Soil class & $\begin{array}{c}\text { Stress from internal pressure } \\
7 \mathrm{MPa} \text { (theory of elasticity) } \\
{[\mathrm{MPa}]}\end{array}$ & $\begin{array}{c}\text { Stress from internal pressure }+ \\
\text { thickness of bulk density } \\
\text { covering } 0.25 \mathrm{~m}[\mathrm{MPa}]\end{array}$ & $\begin{array}{c}\text { Stress from internal pressure }+ \\
\text { thickness of bulk density } \\
\text { covering 0.8m [MPa] }\end{array}$ & $\begin{array}{c}\text { Stress from internal pressure }+ \\
\text { thickness of bulk density } \\
\text { covering } 1.5 \mathrm{~m}[\mathrm{MPa}]\end{array}$ \\
\hline F4 & 268.55 & 250.37 & 259.73 & 269.66 \\
\hline S4 & 268.55 & 244.9 & 253.14 & 255.36 \\
\hline G4 & 268.55 & 249.26 & 250.40 & 251.62 \\
\hline
\end{tabular}

\subsection{Non-uniform environment}

Due to repairs, and of the installation of a strain measurement system, a gas pipeline with reduced working gas pressure was located in an open earthwork cutting. After those works were finished, the cutting was again buried in light soil, which eventually settled. The phenomenon of the non-homogeneity of soil was analyzed similarly as the previous chapters.

The modeled DN 1200 pipeline with a wall thickness of $18.9 \mathrm{~mm}$ was deposited in the trench, which was backfilled with class F3 soil with a soft consistency with a modulus $\mathrm{E}=4 \mathrm{MPa}$ and a unit weight $\gamma$ $=18 \mathrm{kN} / \mathrm{m}^{3}$. The original soil was class $\mathrm{G} 3$ gravel with a modulus $\mathrm{E}=$ $70 \mathrm{MPa}$ and a unit weight $\gamma=19 \mathrm{kN} / \mathrm{m}^{3}$. The resulting deformation and strains from the internal pressure in the pipe $(6.5 \mathrm{MPa})$ and the bulk weight are shown in Figures 11 and 12.

The resulting stress from the combination of internal pressure (6.5 MPa) and the bulk weight for the given boundary conditions was 205.4MPa (Fig. 12). This value is close to the theoretical value of 209.79MPa, which was calculated using the theory of elasticity.

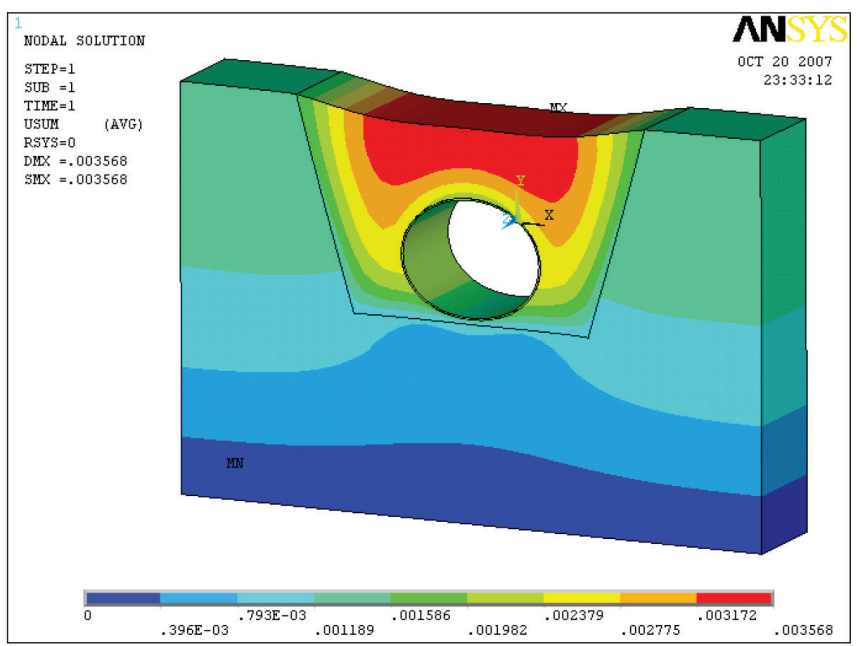

Fig. 11 Deformations from bulk weight and internal pressure [kPa]

\subsection{Landslide acting perpendicularly to a pipe's axis}

This sub-chapter analyses the effect of a landslide in a direction perpendicular to the axis of a pipe. The soil block modeled was $1 \mathrm{~m}$

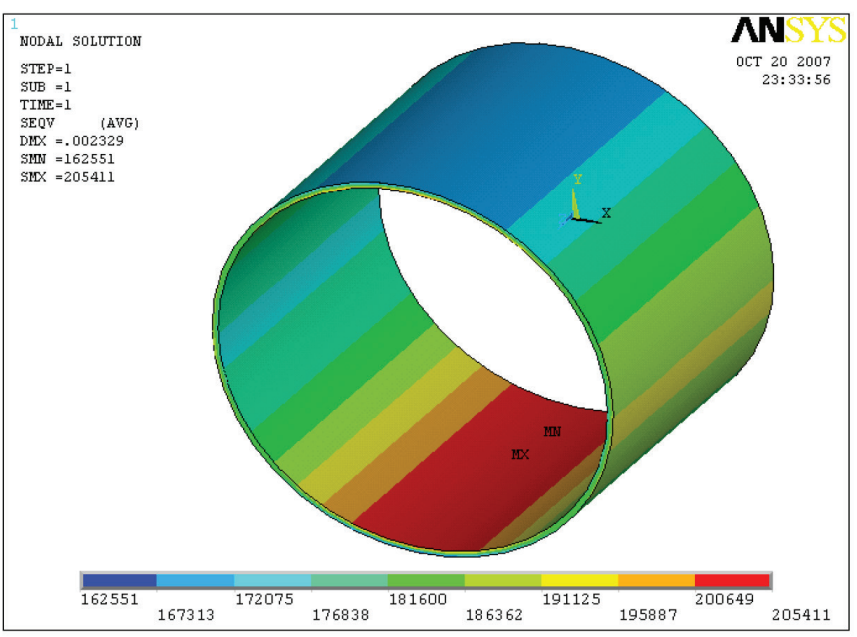

Fig. 12 Von Mises strains from bulk weight and internal pressure $[\mathrm{kPa}]$

thick, and the DN 1200 pipe had a wall thickness of $18.9 \mathrm{~mm}$. Internal gas pressure of 6.5 MPa was simulated in the pipe (Fig. 13). In the first model, the surrounding class F3 soil was homogeneous with a modulus of $12 \mathrm{MPa}$ and had a specific gravity weight of $18 \mathrm{kN} / \mathrm{m}^{3}$. 
The second model used grade G3 gravel with a modulus of 70MPa.

The resulting deformation and strains from the bulk weight for the class F3 soil are shown in Figures 16 and 17 and those from the G3 gravel in Figures 19 and 20.

Based on the results obtained, it can be concluded that the shapes and values of the deformations are very similar when considering all the soil classes. It is therefore possible to use the same loading scheme for the analysis of a pipe in all kinds of soils by varying only the value of the bulk weight of the soil. The pipe is affected by the soil at a distance of about three meters from the outer pipe face, $1 \mathrm{~m}$ below the pipe, and the whole covering layer above the pipe. Overall, this affected area has dimensions of $13.4 \mathrm{~m}^{2}$.

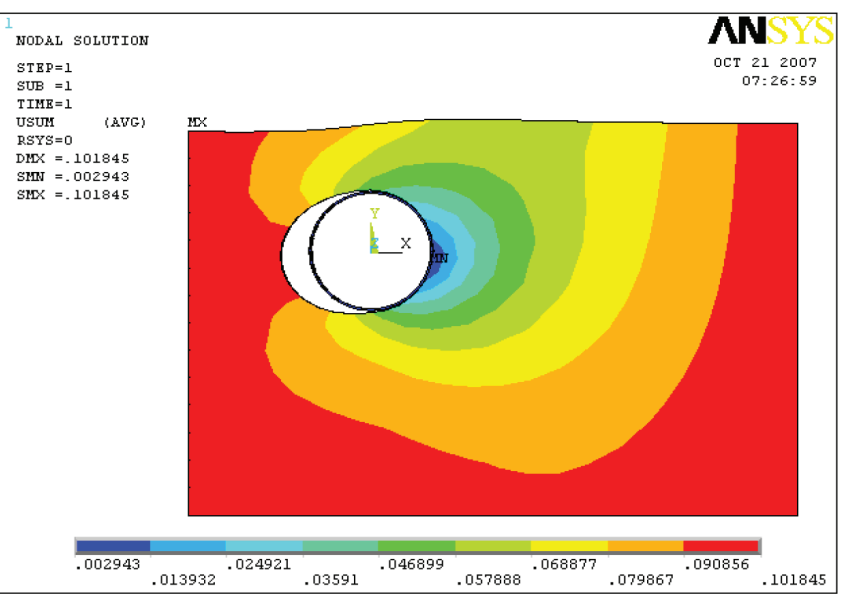

Fig. 14 Deformations from the lateral slide $(100 \mathrm{~mm})$ in the F3 class soil [m]

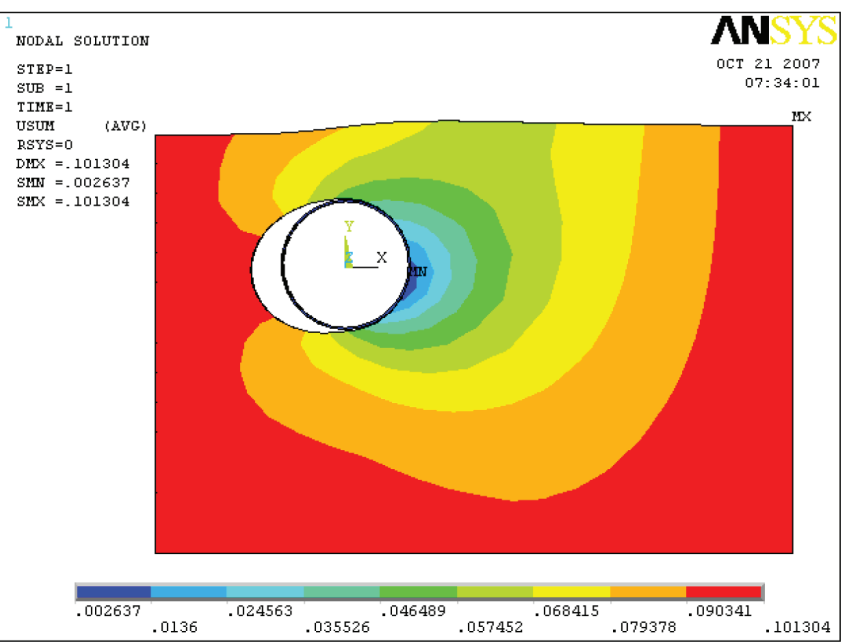

Fig. 16 Deformations from the lateral slide $(100 \mathrm{~mm})$ in the G3 class soil $[\mathrm{m}]$

\subsection{Friction between the soil and pipe}

A finite element model (FEM) was created to evaluate the effect of friction. A soil block from F3 soil and a DN1200 pipeline with a wall thickness of $18.9 \mathrm{~mm}$ was modeled. The models were the same; only the friction coefficient changed $(0.1,0.5,0.9)$. The pipe was pushed by the block of soil with a force of $5 \mathrm{kN}\left(1.45 \mathrm{kN} / \mathrm{m}^{2}\right)$. The

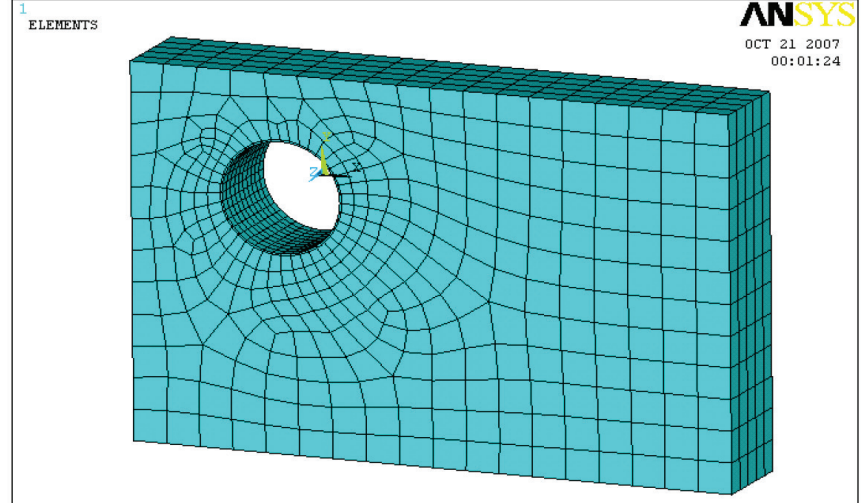

Fig. 13 Soil segment model

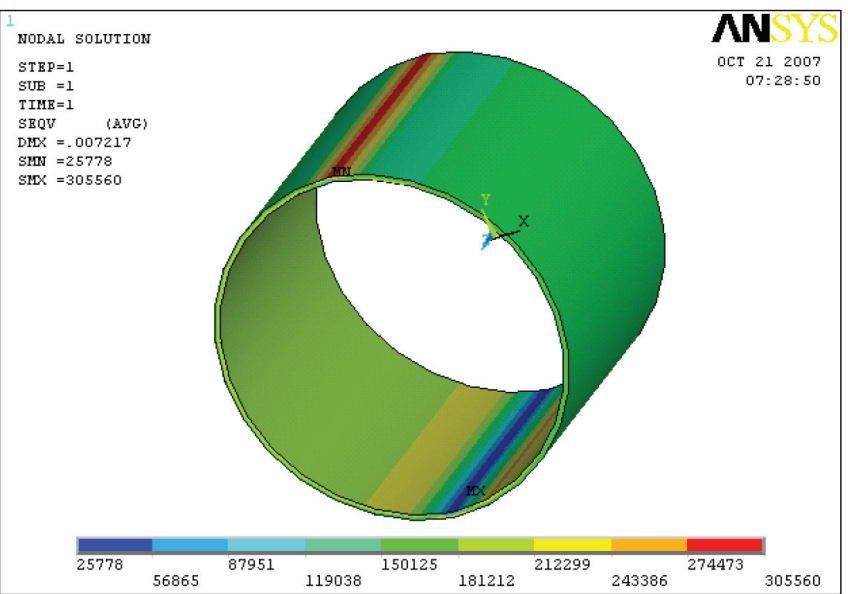

Fig. 15 Von Mises strains in the F3 class soil [kPa]

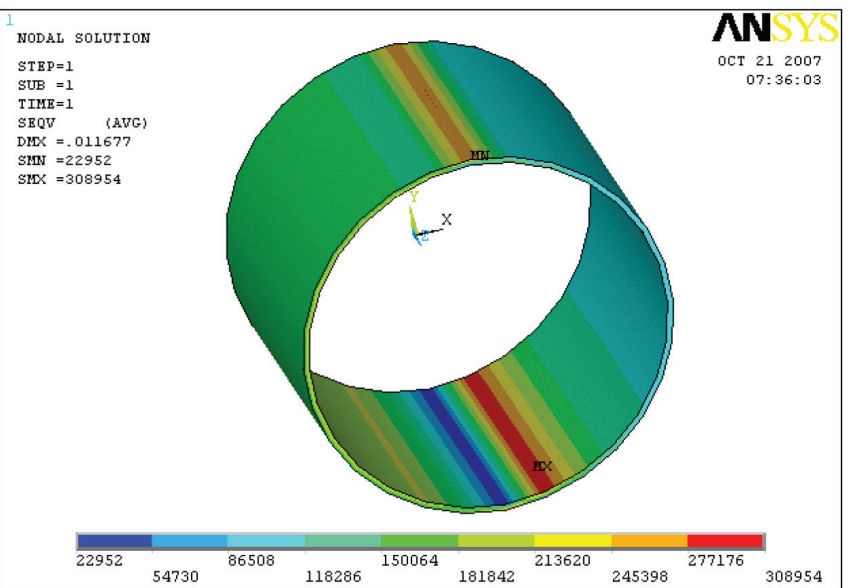

Fig. 17 Von Mises strains in the F3 class soil [kPa]

deformations by the different friction coefficients are shown in Figures $22-24$.

The great effect of the friction coefficient on the deformation can be seen in the figures below. The deformations range from $16.1 \mathrm{~mm}$ with a friction coefficient of 0.1 to $1 \mathrm{~mm}$ with a coefficient equal to 0.9 . 


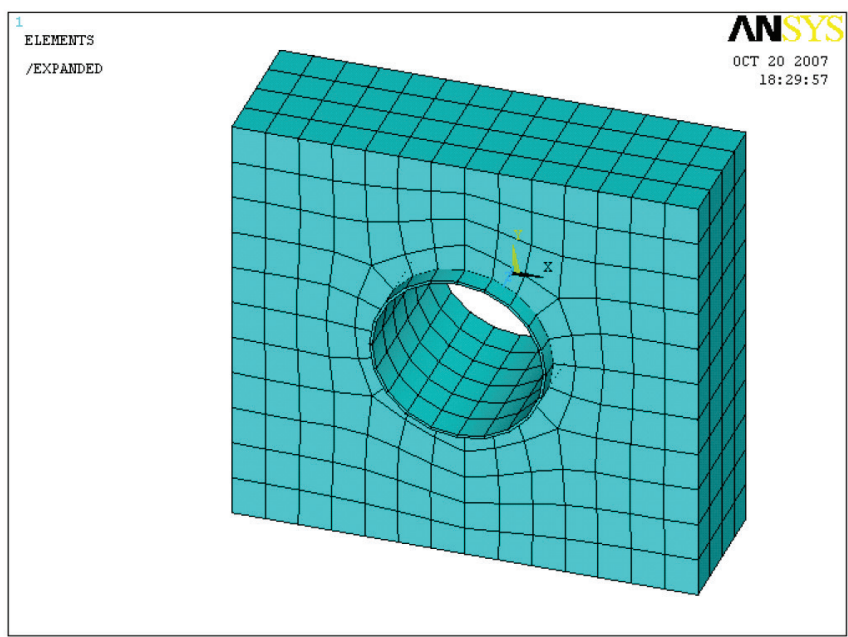

Fig. 18 Analyzed model

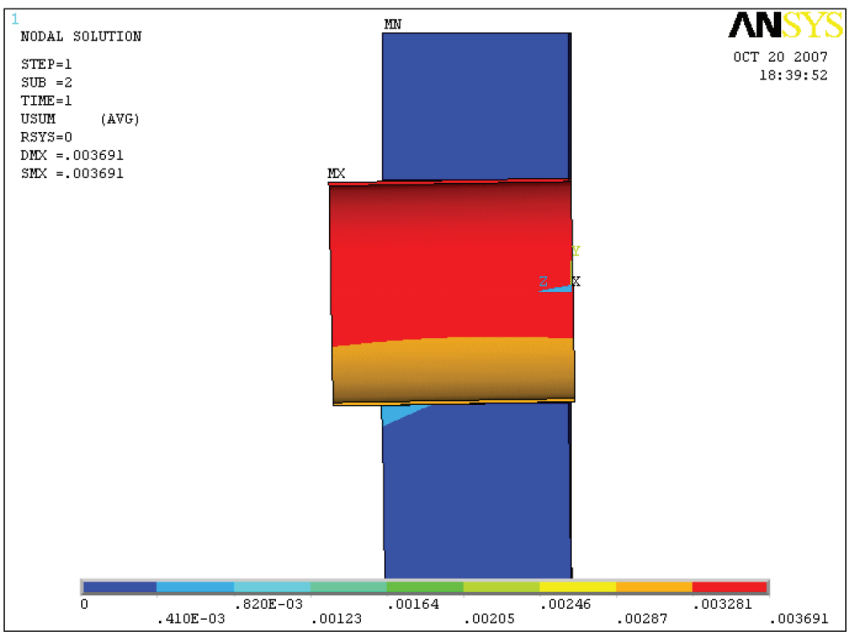

Fig. 20 Deformations $[\mathrm{m}]$ - soil F3, friction coeff. 0.5

\section{EXPERIMENTAL VERIFICATION OF STRAIN LEVEL FROM LONGITUDINAL LANDSLIDES}

For the simulation of a longitudinal slide, a $12.9 \mathrm{~m}$ long part of a pipe was used. It was located at an anchorage block that was oriented towards a field in Nitra, Slovakia. The soil layer covering was 1100 $\mathrm{mm}$ thick on both ends of the test segment. The pipe was insulated by a wrapped asphalt coating which was attached in certain locations.

A $600 \mathrm{~mm}$ section of the pipe next to the anchor block was cut out to enable the insertion of a pair of hydraulic presses. The pipe was placed in an intact $5 \mathrm{~m}$ long soil block; both of its ends were accessible from the trenches (Fig. 22).

The pipe was pushedin the axial direction by the pair of ENERPAC RC-756 hydraulic presses. The shift itself was measured by a HBM WA200 track sensor mounted on top of the pipe. A maximum constant power of $100 \mathrm{kN}$ was required for the pipe to move.

After finishing the experiment and removing the presses, the pipe moved about $80 \mathrm{~mm}$, and the cracks remained open. They spread from the natural surface of the body around the outer surface of the pipe at a distance from 800 to $1200 \mathrm{~mm}$, which is about the value of the pipe's dimension lines (Fig. 24). The resulting surface resistance of the depressurized pipeline against the axial shift for the Nitra location in dry soil was $3.8 \mathrm{kN} / \mathrm{m}^{2}$, which is equal to $13.03 \mathrm{kN} / \mathrm{m}$ of the pipe.

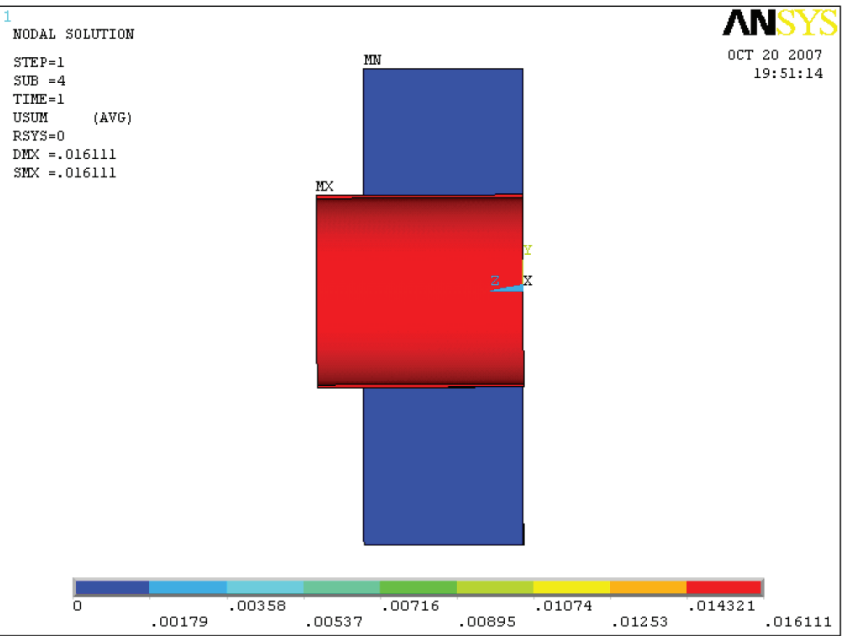

Fig 19 Deformations [m] - soil F3, friction coeff. 0.1

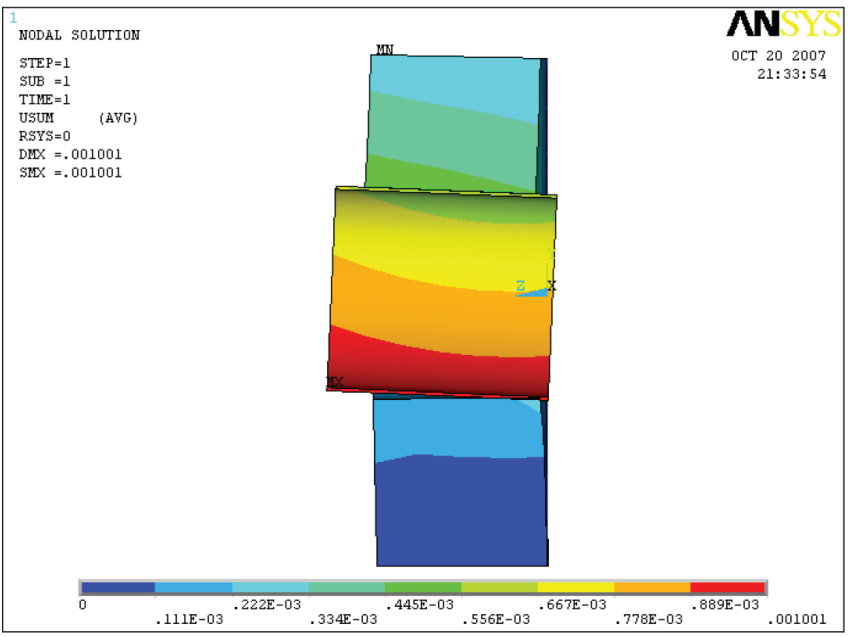

Fig. 21 Deformations [m] - soil F3, friction coeff. 0.9

A comparison between the theoretical model and the experiment is difficult. The experiment showed that the friction coefficient in the actual structure ranges between 0.1 and 0.3 .

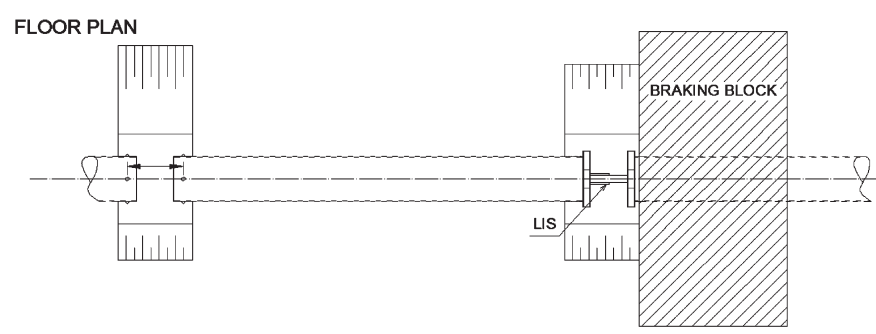

LONGITUDAL SECTION

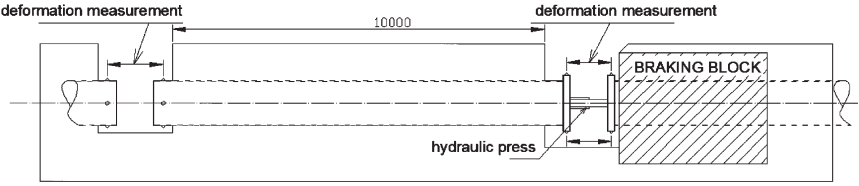

Fig. 21 Floor plan of the experiment simulating an axial slide 


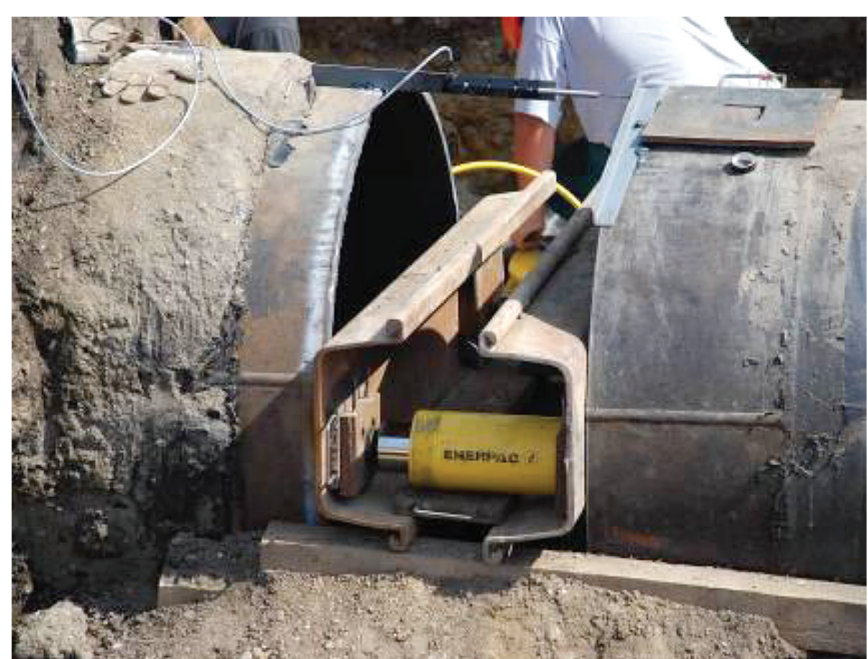

Fig. 22 The loading from hydraulic presses

\section{CONCLUSIONS}

Simple calculations of the strain in the walls of pipelines based on the theory of elasticity are presented in this article. This method was used in the 1970's to design gas pipelines, but is nowadays outdated and economically inefficient. It is necessary to know all the strain components in a pipe, especially for the purpose of the reconstruction and evaluation of experimental measurements. Several factors which affect the state of strain in a pipe were shown. The reserves of the material resistance were calculated. This simple method of calculation had a certain measure of safety, because the calculated reserve of the material resistance obtained from the FEM calculations was higher in all the cases.

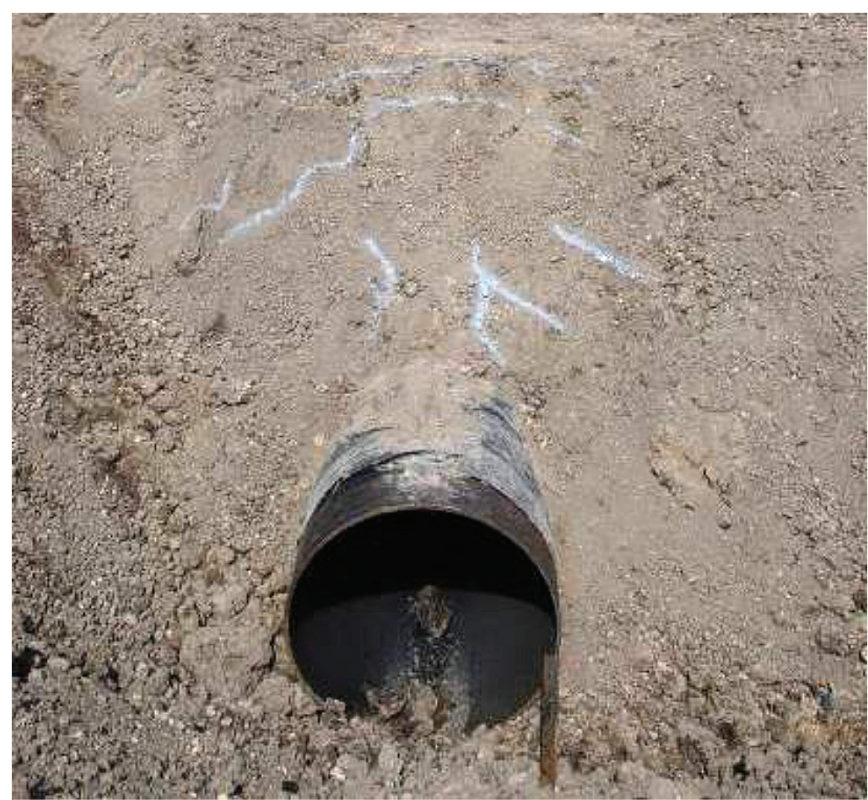

Fig. 23 Corrupted soil block

\section{REFERENCES}

Brodniansky, J. - Magura, M.: Research and Development Task, Analysis of Pipeline Action in Areas Exposed to Landslide, SUT, Faculty of Civil Engineering, 2009

Il'kaev, R. - Seleznev, V. - Aleshin, V. - Klishin, G.: Numerical Simulation of Gas Pipeline Networks. Moscow: URSS, 2005

Turček, P. - Hulla, J.: Foundation Engineering, Bratislava: Jaga group, 2004

Peijung: Numerical Modeling of Pipe - Soil Interaction under Oblique Loading, Journal of Geotechnical and Geoenviromental Engineering. Vol. 131, No.2, February 2005, ASCE, 2005

3D Finite Element Analysis of Pipe-soil Interaction - Effects of Groundwater, Final Report C-Core Report R-02-029-076, Canada, Feb. 2003

Robert, D. J. - Thusyanthan, N. I.: Numerical and experimental study of uplift Mobilization of Buried Pipelines in Sands, Journal of Pipeline Systems Engineering and Practice, Vol. 6, No. 1, 1 Feb. 2015, ISSN: 1949-1190
S. Zhang, J. - Liang, Z. - Zhao, G.: Mechanical Behaviour Analysis of a Buried Steel Pipeline Underground Overload, Engineering Failure Analysis, Vol. 63, May 01, 2016, pp. 131-145, ISSN: 13506307, Elsevier, 2016

Scheiner, S. - Pichler B. - Hellmich Ch. - Eberhardsteiner, J.: Loading of Soil-covered Oil and Gas Pipelines due to Adverse Soil Settlements - Protection Against Thermal Dilatation-induced Wear, Involving Geosynthetics, Computers and Geotechnics, Vol. 33, No. 8, Elsevier, 2006

Newson, T. A. - Deljoui, P.: Finite Element Modelling of Upheaval Buckling of Buried Offshore Pipelines in Clayey Soils, ACSE 2007 